\title{
Surviving the consumer jungle
}

A young friend came to see me the other day, visibly upset. I had known him since he started medical school, had encouraged him through plastic surgery training and watched him begin practice. I had tried not to give him advice, knowing how quickly this antagonizes people and how secretive people get when they don't take the advice given. I think that the best of them don't take my advice, preferring to test their own judgment by solving problems through trial and error. I have learned to ask, "what do you think is the best thing to do?" and then listen quietly, acting as a neutral sounding board.

My friend was visibly agitated and I asked him what was wrong.

"I've just been sued," he said. He looked terrible. For someone in his 30s and in the peak of health; he looked pale, agitated and anxious.

I thought of all the things that I could have said; that it was not his fault (but wondered if it was), most of us will be sued at some time or other, or that he did his best so what more could he have done, but all these assurances seemed dry and hollow. So I just asked him what had happened, knowing that he was not supposed to discuss it, but that he needed to and that I would not tell a soul.

He began, "I saw the patient, a woman of about 40 who came to me wanting liposuction of her abdomen. She said she heard how good I was from my advertisement in Mountbatten Life magazine. She had the usual lower abdomenal roll, and love handles on each side. She didn't want an abdomenoplasty because she didn't want a scar. She was about 5'6" and weighed 190 pounds. Her blood pressure was 160 over 100 but she said it was just white coat syndrome and when she took it at home it was always normal. She told me not to worry about it."

At this point, my friend became angrier than I had ever seen him. He had the chart with him and shook it in the air until some of the pages flew out and landed on the floor beside me. "I'm sorry I ever laid eyes on her," he said, glowering and his body tensing.

"So you did the liposuction-lower abdomen and flanks?" I said quietly.

"Sure. I told her I was experienced and recovery was fast. I did it a week later like she wanted and she was happy with the fee. I did her under local and sedation saving her an anesthetic fee."
"What was your fee, if you don't mind me asking?" I inquired.

"I advertise my fees, which is only fair," he said. "Fifteen hundred dollars, including surgery and operating room charges, done in my own clinic, which I built as soon as I went in to practice."

"Pretty reasonable - considering," I said.

"I rely on volume. Reasonable fees, large volume," he said and smiled for the first time.

"So then what happened?" I asked.

"She came back and said her abdomen wasn't flat like I promised her."

"Did you promise her?" I asked quietly.

"I said there was no guarantee, and did a full consent on liposuction, listing everything that could go wrong, or at least my nurse did. I've gotten too busy to talk to patients for long. I meet them, but patients feel more comfortable with my nurse than they do talking to me. And she signed the consent form."

"When did she sign it?" I asked.

"I don't know," he said flipping through his chart. "There it is, the same day as surgery witnessed by the nurse."

"What then?" I asked. My questions were getting shorter.

"She wanted me to do a mini-abdomenoplasty. You know, with a short scar, angled up at the sides - a thong bikini type with the scar fitting under the thong strings."

I paused as I looked at him, waiting for him to continue.

"I did it, but the problem was, it was only right that she pay for it. She agreed to suction, which she wanted in the first place. It was her decision. Now she wanted me to pay for her mini-abdomenoplasty since suction in her words, 'didn't work'."

"So we argued, and she said, if I didn't pay for it she would report me to the college."

I thought of injecting a note of humour into the conversation by asking him if he meant the college of fishermen and sturgeons but decided that then was not the time.

"I've never had a complaint to the college before, so I did it. I paid for her mini-abdomenoplasty. It was a bunfight because I did it under local to save money. It was a big abdomen and she bled a lot; hypertensive you know."

I was getting to the point where I was afraid to ask what happened then because I had never been particularly impressed with mini-abdomenoplasties, especially the kind 
with upward slanting scars. How would you cover the scars if styles changed? I said nothing and looked at him.

"She didn't like that either. She showed me the fat on her upper abdomen which was still there, and looked bigger now that her lower abdomen was flatter. She said she gained 15 pounds after surgery with all the stress of not having the right operation. This time she told me I should have done a full abdomenoplasty, and said if I didn't do it, and do it no charge, 'I would hear from her'."

"I knew what that meant. She said we had entered into a contract to make her happy."

"You did her abdomenoplasty, didn't you?" I asked.

"Sure, who wouldn't under the gun like that. I did it to make her happy. I figure it was worth the cost."

"What did it cost?" I asked.

"Considering the operating room in hospital, the anesthetist, overnight stay since it was cosmetic, and my fee for a full abdomenoplasty, four thousand five hundred dollars, plus tax! It cost $m e$, not her!" he said.

I steeled myself to sit quietly and use my meagre reserve of Aequanimitas - that imperturbability William Osler said that all physicians must have.

I didn't have long to wait.

"She sued me," he said, clutching the document in his hand. I saw the familiar slender subpoena in his hand.

A line ran through my mind.

If you choose not to defend this action within 30 days... I was not unfamiliar with the wording.

"I did everything right," he said. "What happened?"

"My friend, you've just been had," I said.

"Go home, write it all out, and analyze what happened."
"You're not very sympathetic," he said ruefully.

"It's only money and your money at that," I said. "She wasn't injured, and that's the important thing."

It was, really, all that I could say, but he looked so dejected.

I saw him again that summer. He looked happy and was full of energy. I read the list that he showed me.

1. Diagnose first, propose treatment later.

2. Find out the patient's goal and explain the way to achieve it (if there is one). Don't start small and work up; surgery is not buying clothing.

3. Anyone in a rush to have elective surgery might be disorganized and afraid he/she will change his/her mind about surgery. He/she might, but only after the operation.

Everyone says there are no guarantees, but patients think, "he wouldn't do the operation if he didn't know I would be better."

4. If patients knew the best operation to do, they wouldn't need me.

"I like your list," I said. "Don't worry about the money; every lesson I learned cost me something - sometimes a lot!"

"Next time we talk, you might have a different problem," I said.

"There isn't going to be a next time," he said determinedly.

I smiled my hidden smile; the one that no one can see, and thought that the only way there wouldn't be a next time is if he stopped learning. As he walked away smiling, cheerful and whistling, I said under my breath, "Don't buy tech stocks either."

John Taylor jrtaylor@inforamp.net 